\title{
Research on User Roles Identification of Crowdsourcing Innovation Virtual Community
}

\author{
Qingliang Meng, Nini Sun \\ School of Management \& Economics, Jiangsu University of Science \& Technology, Zhenjiang, China \\ Email: mengzhi007@163.com
}

How to cite this paper: Meng, Q.L. and Sun, N.N. (2019) Research on User Roles Identification of Crowdsourcing Innovation Virtual Community. Journal of Service Science and Management, 12, 421-438. https://doi.org/10.4236/jssm.2019.123029

Received: March 4, 2019

Accepted: April 19, 2019

Published: April 22, 2019

Copyright $\odot 2019$ by author(s) and Scientific Research Publishing Inc. This work is licensed under the Creative Commons Attribution International License (CC BY 4.0).

http://creativecommons.org/licenses/by/4.0/

(c) (i) Open Access

\begin{abstract}
Crowdsourcing innovation is a new model for enterprises to acquire knowledge of external networks and achieve innovation objectives effectively. Its organizational form is relatively loose, the participants are free and voluntary, and come from a wide range of sources. Deeply understanding the heterogeneity and contribution behavior of crowdsourcing innovation participants is very important to crowdsourcing innovation practice. Taking the IdeaStorm crowdsourcing community as the research object, the data related to user interaction and contribution is captured. Through social network analysis combined with cluster analysis to explore the heterogeneity of user interaction behavior and contribution behavior and finally establish five different user roles, they have different importance to support the effective operation of the community. This study will be helpful to understand the crowdsourcing innovation mode and provide theoretical guidance for the effective management of crowdsourcing innovation activities in enterprise community.
\end{abstract}

\section{Keywords}

Crowdsourcing Innovation, Social Network Analysis, User Roles, Identified

\section{Introduction}

At present, more and more companies realize that innovation activities based solely on internal resources have been difficult to meet the rapidly growing market demand and increasingly fierce commercial competition. In 2006, Howe first presented "crowdsourcing", and the concept of crowdsourcing is defined as the fact that a company or organization outsources work tasks performed by employees in the past to a non-specific (and often large) mass network in a free and voluntary manner [1]. As a new type of innovation, crowdsourcing innovation has been widely concerned by the theory and practice. Its main idea is: the 
enterprise will outsource the innovation problems encountered by the self-built virtual community or the third-party crowdsourcing platform to the external network users. That is, enterprises solve internal innovation problems by acquiring the knowledge resources of external network users [2]. The crowdsourcing innovation model breaks the boundaries of innovation organizations and fully develops the wisdom of the public, thus effectively reducing the cost of innovation and reducing the risk of innovation. To this end, more and more enterprises adopt or gradually develop suitable crowdsourcing innovation models: Dell (DELL) founded the IdeaStorm crowdsourcing community. So far more than 27,800 ideas have been submitted, more than 550 public ideas have been implemented; Starbucks relies on the My StarbucksIdea.com crowdsourcing innovation community to continuously collect external public creativity to leverage the power of the online community to promote brand awareness and gain innovative ideas for products and services; Xiaomi's MIUI community is an important platform for Xiaomi to develop seamless and open innovation activities, with more than 47 million registered users and thanks to "the full participation of the masses", Xiaomi has grown rapidly. At home, many third-party crowdsourcing platforms, such as ZBJ.com, Taskcn, EPWK.com and other third-party crowdsourcing platforms have poured into the market one after another, and have carried on beneficial exploration to the practice and application of crowdsourcing innovation mode.

It can be seen that the crowdsourcing innovation model has achieved good results in practice. Considering that crowdsourcing innovation is loosely organized, mass participation is free and voluntary, and is not subject to restraint. Therefore, the proper management of a wide range of participants in the crowdsourcing innovation community and the guidance and regulation of their behavior will be the key to the effective operation of the crowdsourcing innovation community. It is pointed out that the stability, persistence and effectiveness of the virtual community depend on the mobilization of the initiators and the ability to adapt and manage the heterogeneity of the masses. David (2008) [3] pointed out that the stability, persistence and effectiveness of virtual communities depend on the ability of the initiator to mobilize, adapt and manage the user's heterogeneity. Welser et al. (2011) [4], Pedersen et al. (2013) [5] argued that in order to manage crowdsourced innovative virtual communities more effectively, it is necessary to understand the heterogeneity of community users' roles and behaviors, including their contribution behaviors, knowledge sharing and social interaction, etc. Füller et al. (2014) [6] pointed out that the participants cooperate and compete in the context of the innovative competition community. The initiative, experience, skills and high heterogeneity in their personal background led to a complex structure in the entire community. Guo et al. (2017) [7] believes that in the crowdsourcing innovation community, where large numbers of people scatter around the world, in the innovation process without touching each other. Their behavior is free and voluntary. They submit solutions, and im- 
prove the creative ideas by guiding the masses to communicate with each other and multi-dimensional interactions, thereby improving the quality of creativity.

Obviously, the above literature discusses the user role and contribution behavior of the virtual community from different perspectives, and has a good guiding significance for understanding the user heterogeneity of crowdsourcing innovation virtual communities. In order to understand the basic dynamics of crowdsourcing innovation communities, better manage crowdsourcing activities, and improve innovative solutions that produce better quality, it is critical to explore community user types and behaviors. This paper will select a more representative crowdsourcing innovation community as the research background, and examine the network structure, user roles and contribution quality of the community. Compared with the existing research, this study will point out the differences in user behavior patterns and explain the different importance of different types of users to the successful operation of the community, in order to provide decision support for the relationship governance and good operation of crowdsourcing innovative virtual communities.

\section{Related Theory}

\subsection{The Connotation and Operation Mode of Crowdsourcing Innovative Virtual Community}

Today, innovation is no longer just the main task of corporate R \& D personnel. Instead, the innovation process is open, and the community is an Internet platform that uses a variety of ideas and ideas from Internet users to create new products for stakeholders. With the development of information technology, the innovative mode of crowdsourcing has a wider application prospect. Participants with different knowledge and skills contribute to their creativity and help businesses accomplish their innovation tasks through the online community [8]. The online community has become an important and widely studied economic and cultural phenomenon. Different communities' environment and purposes must have different modes of operation.

Under the background of booming Internet technology, crowdsourcing innovation with the public participation as the core, it is a new business model with large-scale innovation and value creation through the Internet platform [9]. Scholars have also interpreted and defined crowdsourcing innovation communities. For example, Schröder et al. (2010) [10] shows that innovation virtual communities are formed that individuals who are free to participate in crowdsourcing activities. They share and interact to build community awareness, and serve collaborative innovation aims. Fan Ting (2012) [11] pointed out that the crowdsourcing community is not only an information system, but also a new social structure based on the Internet. Tung et al. (2017) [12] pointed out that resources derived from crowdsourcing platforms are not only tangible, but also intellectual and virtual. This makes the platform an effective tool for social enterprises to make the most of their resources and help them achieve their inno- 
vation goals. Therefore, it is believed that crowdsourcing innovation virtual communities use Internet technology to provide a virtual environment for the public to participate in internal innovation and interaction, and users can promote innovation project development through cooperation, sharing and competition. Today, the network is full of diverse crowdsourcing services. Some crowdsourcing activities do not have currency transactions. Wikipedia is such a typical collaborative community. Another example, Dell's self-built crowdsourcing innovation community, IdeaStorm, allows users to submit personal ideas, comment or vote on other people's creative content to improve the quality of ideas in such interactive discussions, and Dell will apply creative practices to ideas that are promoted and score higher. Furthermore, InnoCentive, a typical third-party crowdsourcing platform abroad, contractor accomplishes the innovation task published on the platform, and when the submitted innovation scheme is adopted by the enterprise, it will receive the amount of reward promised by the enterprise. The goals of these platforms are not only to capture users, but also to build their interactive contributions. Many collective intelligence applications rely on real-time management and understanding of large amounts of user-generated data. Community-generated data requires an efficient system to collect and connect these data between users to better serve their own business [12].

In addition, many scholars at home and abroad have made some important achievements in the theory and empirical research of crowdsourcing virtual communities from various angles. Brabham (2008) [13] used the iStockphoto community as a background to obtain community user-related data through online surveys, explored the motivation of online user participation, and pointed out that the desire to obtain money, develop personal skills and gain interest is the strongest motivation of the participants. Zhang et al. (2012) [14] takes Chinese Wikipedia as an example to examine the three indicators of the participants' degree centrality, betweenness centrality and closeness centrality from the perspective of social network to determine their position in the community network structure. There is a strong causal relationship between the user's network location and the contribution behavior. Fuger et al. (2017) [15] pointed out that Internet platform participants can interact with other like-minded peers, build relationships, and build community awareness; users can collaborate, discuss, share insights, and learn from others' overall knowledge and feedback. Improve your position in the community. Xia Enjun et al. (2017) [16] conducted an investigation on the ongoing participation behavior of online crowdsourcing participants with the Xiaomi crowdsourcing community. Through empirical research, it clearly pointed out that knowledge acquisition, emotion, socialization and interest are important motivations for the public. All in all, scholars' research on crowdsourcing innovation communities has laid a solid theoretical foundation for the development of this field.

In the field of crowdsourcing research, although the division of crowdsourc- 
ing participants is different, the meaning is generally the same, that is, the task publisher, the contractor, and the crowdsourcing innovation platform. The task publisher can be an enterprise, an individual or a non-profit organization. Under the condition of realizing that its resources are scarce and it is difficult to solve the innovation problem, it can achieve the innovative purpose by absorbing, integrating and developing external resources; the contractor is also active. The public on the Internet platform, they can be professionals or amateurs. They are completely free and willing to participate in crowdsourcing activities without any restrictions. Any independent individual is a collection of knowledge and information, and has potential value that can be exploited and utilized [17]. The crowdsourcing innovation platform is the communication bridge between the task publisher and the contractor. Whether the operational effect is perfect determines the durability and effectiveness of crowdsourcing activities. Wang Yanjie (2010) [18] divides crowdsourcing communities into two forms based on the type characteristics of crowdsourcing: collective intelligence crowdsourcing communities (such as Taskcn.com, Zhubajie) and mass creation communities (such as Youku). For the time being, crowdsourcing innovation platforms generally have two modes of operation: enterprise self-built virtual communities and third-party crowdsourcing platforms. As shown in Table 1.

Table 1. Comparison of crowdsourcing innovation community types.

\begin{tabular}{|c|c|c|c|}
\hline $\begin{array}{c}\text { Crowdsourcing } \\
\text { innovation virtual } \\
\text { community }\end{array}$ & Characteristics & $\begin{array}{c}\text { Degree of } \\
\text { collaboration }\end{array}$ & Typical Case \\
\hline $\begin{array}{l}\text { Enterprise self-built } \\
\text { virtual community }\end{array}$ & $\begin{array}{l}\text { The virtual community developed } \\
\text { by the enterprise relying on } \\
\text { Internet technology integrates } \\
\text { opinions and suggestions } \\
\text { (user-generated content) of a } \\
\text { wide range of users on product } \\
\text { products for product promotion } \\
\text { and commercial development. } \\
\text { And assist enterprises to } \\
\text { better understand the needs } \\
\text { and wishes of users } \\
\text { [15] [17] [18]. }\end{array}$ & High & $\begin{array}{l}\text { Ideastorm, } \\
\text { My Starbucks } \\
\text { Ideas; } \\
\text { MIUI }\end{array}$ \\
\hline $\begin{array}{c}\text { Third-party } \\
\text { crowdsourcing } \\
\text { platform }\end{array}$ & $\begin{array}{l}\text { This kind of platform is a } \\
\text { crowdsourcing agency that } \\
\text { connects the contractor (enterprise, } \\
\text { individual or non-profit } \\
\text { organization, etc.) with the } \\
\text { contractor (social public } \\
\text { participant); it integrates } \\
\text { the wisdom of the } \\
\text { enterprise to solve the innovation } \\
\text { problems faced by the enterprise, } \\
\text { and the submitted solution is } \\
\text { finally adopted. The user gets } \\
\text { the corresponding reward [17]. }\end{array}$ & Low & $\begin{array}{c}\text { Innocentive; } \\
\text { Taskcn.com; } \\
\text { zhubajie }\end{array}$ \\
\hline
\end{tabular}




\subsection{The Role of Crowdsourcing Innovative Virtual Community Users}

Crowdsourcing often produces distinct virtual communities [14]. Previous research has provided important insights into the identification and conceptualization of different user roles in various online communities. For example, Hautz et al. (2010) [19] explored the role of users in the innovation competition by collecting user data from the Swarovski Jewelry Design Competition, and divided the innovative community users into eight types: Motivator, attention-grabbing; Motivator; Attention attractor; Passive user; Attention attractor, motivating idea generating; Motivator, idea generating; Attention attractor, idea generating; Idea generator. Koch et al. (2013) [20] focused on an open government platform, using social network analysis to derive the core-edge structure of the overall network structure of the platform; measuring the degree centrality of penetration by the number of comments received by users, with the number of comments submitted by users By measuring its outreach, users are divided into six categories: motivator, attention attractor, idea generator, communicator, master, passive user. Lu et al. (2014) [21] used the crowdsourcing user support forum as an example to explore the impact of core-edge network structure on the effectiveness of knowledge sharing. By establishing a dynamic structure model, users are more inclined to answer questions raised by users at the core position. Therefore, it is pointed out that the core-edge network structure hinders the knowledge flow of the community and is not conducive to knowledge sharing among users. $\mathrm{Li} \mathrm{Li}$ feng (2017) [22] combined with relevant theories to analyze the Xiaomi community example, based on the environmental characteristics of the innovation community, establish the measurement dimension of customer classification, cluster analysis based on the indicators of customer participation intensity, and obtain enthusiastic customers, actively engage customers and demand customers, and analyze the behavioral characteristics and roles of users in the community.

The classification of virtual community user roles is shown in Table 2. Scholars often use participation frequency, interaction behavior, contribution, etc. as indicators of different user roles [23] [24] [25]. This article will include more effective user classification indicators, enhance the reliability of user classification results, and explore the heterogeneous behavior of community users more scientifically.

\section{Empirical Research}

\subsection{Data Sources}

This article is based on Dell's crowdsourcing innovation virtual community IdeaStorm. In 2007, Dell launched the user feedback website to solicit opinions on product design, marketing, and technical support. IdeaStorm was created to give a direct voice to their customers and an avenue to have online "brainstorm" sessions to allow you the customer to share ideas and collaborate with one another and Dell. Our goal through IdeaStorm is to hear what new products or 
Table 2. User roles correlation research.

\begin{tabular}{|c|c|c|c|}
\hline Author & Classification indicator & User Type & Method \\
\hline $\begin{array}{l}\text { Toral et al. } \\
\text { (2010) [26] }\end{array}$ & $\begin{array}{l}\text { Out-degree, } \\
\text { betweenness }\end{array}$ & $\begin{array}{l}\text { Edge users, general users, } \\
\text { core users }\end{array}$ & Network analysis \\
\hline $\begin{array}{l}\text { Füller et al. } \\
(2014)[6]\end{array}$ & $\begin{array}{l}\text { Out-degree, in-degree, } \\
\text { the number of } \\
\text { contribution }\end{array}$ & $\begin{array}{l}\text { Socializer, idea generator, } \\
\text { master, efficient } \\
\text { contributor, passive } \\
\text { ides generator, passive } \\
\text { commentator. }\end{array}$ & $\begin{array}{l}\text { Social network } \\
\text { analysis and } \\
\text { Cluster analysis }\end{array}$ \\
\hline $\begin{array}{l}\text { Liu et al. (2016) } \\
\text { [27] }\end{array}$ & $\begin{array}{c}\text { User engagement } \\
\text { behavior (contribution } \\
\text { value, participation } \\
\text { level) }\end{array}$ & $\begin{array}{l}\text { Potential users, Core } \\
\text { Users, General Users, } \\
\text { And Powerful Users }\end{array}$ & $\begin{array}{l}\text { Regression } \\
\text { analysis }\end{array}$ \\
\hline $\begin{array}{l}\text { Qi et al. (2016) } \\
{[28]}\end{array}$ & $\begin{array}{l}\text { Idea submitted, Scores, } \\
\text { comment submitted }\end{array}$ & $\begin{array}{l}\text { Core Users, Active Social } \\
\text { Users, Glamorous Social } \\
\text { Users, Active and } \\
\text { Innovative Users, } \\
\text { Effective Innovative } \\
\text { Users, Passive Users }\end{array}$ & Cluster analysis \\
\hline $\begin{array}{c}\text { Guo et al. (2017) } \\
\text { [7] }\end{array}$ & $\begin{array}{l}\text { The number, } \\
\text { popularity, and } \\
\text { impact of user creation } \\
\text { in the community }\end{array}$ & $\begin{array}{l}\text { Project leader, Active } \\
\text { designer, Generalist, } \\
\text { Communicator, Passive } \\
\text { designer, Observer }\end{array}$ & $\begin{array}{l}\text { Social network } \\
\text { analysis and } \\
\text { Cluster analysis }\end{array}$ \\
\hline $\begin{array}{l}\text { Fuger et al. } \\
(2017)[15]\end{array}$ & $\begin{array}{l}\text { Out-degree, in-degree, } \\
\text { the number of } \\
\text { contribution }\end{array}$ & $\begin{array}{l}\text { Collaborator, Contributor, } \\
\text { Allrounder, Passive User }\end{array}$ & $\begin{array}{l}\text { Cluster and social } \\
\text { network analysis }\end{array}$ \\
\hline
\end{tabular}

services you'd like to see Dell develop. Users can post articles, promote articles, downgrade, and comment on articles. Today, the platform has more than 28,300 creative submissions, more than 748,000 votes, more than 103,000 comments, and more than 550 ideas implemented. Use the web crawler Octopus Collector (version 6.4) to get creative projects submitted by 75 sponsors in Dell's implemented projects, and 1195 users submit 4128 comments. And the number of ideas they submitted on the community. The Part of raw data mode is shown in Table 3.

\subsection{Methodology and Measures}

1) Methodology

Applying social network analysis (SNA) and network measurement (out-degree, in-degree, betweenness) to visualize and explain the network structure of the community. Based on individual user network measurement and user contributions, we perform cluster analysis and detect different user roles. Moreover, we compare the quality of submitted ideas in identified user roles and compare the structural positions of these user roles.

Social network analysis (SNA) is both a method and a perspective. In the process of virtual community user interaction, a single user is bound to be influenced by social relationships and their network structure, which in turn 
Table 3. Basic data model.

\begin{tabular}{cccc}
\hline \multirow{2}{*}{ Sponsors' ID } & Commenters' ID & \multicolumn{2}{c}{ Ideas_submitted } \\
\cline { 3 - 4 } 03codyn & rarmasu & Sponsors & Commenters \\
202780 & javaprog07 & 0 & 1 \\
aaron.axvig & gautam & 2 & 1 \\
badblood & thebittersea & 0 & 5 \\
caiyongyong & smotchberry & 221 & 16 \\
$\ldots$ & $\ldots$ & 0 & 7 \\
$\ldots$ & $\ldots$ & & 179 \\
zorath & jervis961 & 0 & 2 \\
zufoo & qgonjon & 0 & \\
\hline
\end{tabular}

affects user decisions [29]. Social relations are complex and changeable. Both qualitative and quantitative research can be used for various social relationships. Social network analysis can precisely satisfy the quantitative discussion of complex social relations, and effectively expand the study of social structure [30]. A social network is a collection of social actors as nodes and their relationships, emphasizing some direct or indirect connection between each actor and other actors in the network.

Cluster analysis is a multivariate analysis technique that classifies research objects according to the characteristics of the research objects. The main purpose is to classify similar things and group individuals (samples) with similar properties (or distances) into one class. Individuals are highly homogenous, with different types of individuals having a high degree of heterogeneity [31]. Among various clustering methods, the $\mathrm{K}$-means clustering method is widely used due to its high efficiency. The basic idea of $\mathrm{K}$-means clustering is to divide $\mathrm{K}$ objects into $\mathrm{K}$ clusters with $\mathrm{K}$ as the parameter, so that the clusters have higher similarity, and the similarity between clusters is lower.

2) User behavior and contribution measurement

Interaction behavior. Out-Degree centrality refers to the output relationship of a node. In this study, out-degree indicates the number of comments submitted by the user. In-Degree centrality refers to the input relationship of a node. In this study, in-degree indicates the number of comments submitted by the user.

Contribution behavior. Number of ideas refers to the number of ideas submitted by users in the community. Users are free to submit their ideas about products or services, which can intuitively reflect the contribution behavior of users.

The cluster is further compared according to the user's betweenness and the quality of submitted ideas. Betweenness measures the user's position in the network structure, which a particular individual lies between various other individuals in the network. At the same time, we measure the quality of users' ideas in terms of their points in the community and the number of votes they have ob- 
tained.

\section{Results}

\subsection{Social Network Analysis}

When a user ID submits a comment to another user ID, it is considered that an interaction relationship is established between the two IDs. Remove duplicate user and sponsor user ID duplicates, as well as isolate points. The processed Excel data is imported into UCINET to generate a $1226 \times 1226$ interactive relationship matrix. UCINET network visualization function is used to draw the social network diagram. As shown in Figure 1, in this directed network diagram, each node represents a user, with a total of 1226 nodes and 1679 connections. At the same time, the social network visualization analysis is carried out for the betweenness, that is, the larger the shape in the figure indicates that the higher betweenness of the node, the more likely it is to be at the core position of the network.

In order to identify different user roles measures of interaction behavior and contribution behavior need to be considered. Table 4 shows descriptive statistics of the measures used as indicators for the participation behavior of users. The maximum value of out-degree is 20 , which is significantly different from the maximum value of in-degree 147. However, the standard deviation of the out-degree is much smaller than the standard deviation of in-degree. This phenomenon indicates that the network structure of the community does not have symmetry in the out-degree and in-degree, which means that the reciprocity of the community is low. In terms of the number of contributions, the maximum value is 359 , the average value is only 3.52 , and the standard deviation is also large, indicating that the user's contribution level is unevenly distributed.

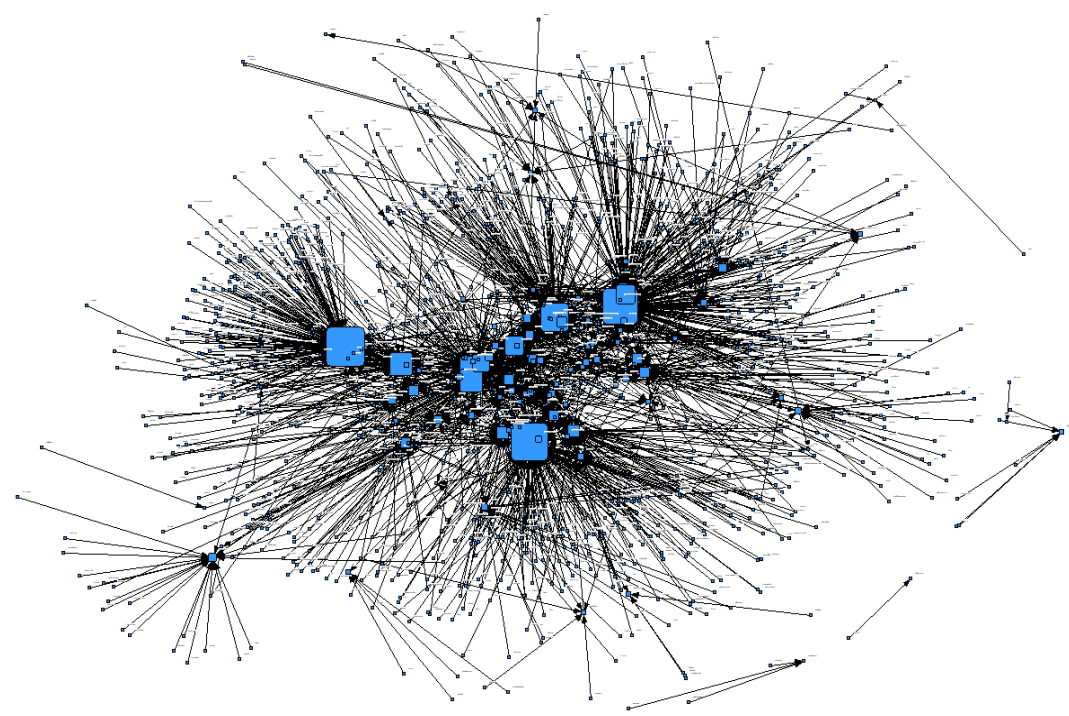

Figure 1. Network of the IdeaStorm community. 


\subsection{Cluster Analysis}

Descriptive statistics have revealed differences in behavior between users. We use the out-degree, in-degree and contributions as indicators to explore the types of users in the community and clarify their differentiation. First, in order to make the clustering results more stable, eliminate a few outstanding users. In this study, we use SPSS22.0 to apply K-means cluster analysis to identify the role of community users. Combined with expert experience, after repeated classification and calculation, it is found that when users aggregate into five categories, presented in Figure 2. The data difference is the most obvious, and the similarity among members in the group is higher. Table 5 shows mean values and standard deviation of the three measures used for each cluster solution and an overview about the distribution of users across the five clusters.

The specific characteristics of the five types of users are analyzed from the perspectives of interactive behavior and contribution behavior, and the individual networks representing the users in various categories will be displayed.

Idea generators: 6 people, accounting for $0.5 \%$. This type of user exhibits a high contribution behavior and a medium level of interaction behavior. Their average contribution is 76.33 , which is much higher than other categories of users. The average of the out-degree and in-degrees is 5.33 and 4.33 respectively, which is at a medium level. This indicates that such users submit a lot of ideas in the innovative virtual community, but less interaction with others. A representative user individual network is shown in Figure 3.

Attention attractors: 19 people, accounting for $1.5 \%$. The behavioral characteristics of such users are mainly high in-degree, low out-degree, and low-contribution behavior. The average value of out-degree and in-degree are respectively 0.47 and 30.95. Obviously, the in-degree values are much higher than other types of users. Moreover, the average number of contributions is

Table 4. Descriptive statistic.

\begin{tabular}{ccccccc}
\hline & $\mathrm{n}$ & Mean & Min & Max & Std Deviation & Variance \\
\hline Out-degree & 1226 & 1.37 & 0 & 20 & 1.662 & 2.762 \\
In-degree & 1226 & 1.37 & 0 & 147 & 9.326 & 86.973 \\
Number of ideas & 1226 & 3.52 & 0 & 359 & 17.795 & 316.658 \\
\hline
\end{tabular}

Table 5. Cluster analysis results: five user roles.

\begin{tabular}{|c|c|c|c|c|c|c|c|c|c|c|c|}
\hline & \multicolumn{2}{|c|}{ Idea generators } & \multicolumn{2}{|c|}{$\begin{array}{l}\text { Attention } \\
\text { attractors }\end{array}$} & \multicolumn{2}{|c|}{ Passive users } & \multicolumn{2}{|c|}{ Motivators } & \multicolumn{2}{|c|}{$\begin{array}{c}\text { Potential } \\
\text { users }\end{array}$} & \multirow{2}{*}{ F-Value } \\
\hline & Mean & $\mathrm{SD}$ & Mean & $\mathrm{SD}$ & Mean & $\mathrm{SD}$ & Mean & $\mathrm{SD}$ & Mean & $\mathrm{SD}$ & \\
\hline Out-degree & 5.33 & 3.45 & 0.47 & 0.88 & 0.97 & 0.17 & 8.59 & 2.20 & 2.34 & 0.71 & 1398.608 \\
\hline In-degree & 4.33 & 5.12 & 30.95 & 15.05 & 0.21 & 1.37 & 0.41 & 1.65 & 0.40 & 2.24 & 740.868 \\
\hline NO. of Ideas & 76.33 & 14.86 & 4.74 & 5.49 & 1.27 & 2.99 & 11.53 & 12.13 & 5.32 & 8.02 & 465.677 \\
\hline Total & \multicolumn{2}{|c|}{6} & \multicolumn{2}{|c|}{19} & \multicolumn{2}{|c|}{1007} & \multicolumn{2}{|c|}{17} & \multicolumn{2}{|c|}{165} & - \\
\hline Percentage & \multicolumn{2}{|c|}{$0.5 \%$} & \multicolumn{2}{|c|}{$1.5 \%$} & \multicolumn{2}{|c|}{$82.9 \%$} & \multicolumn{2}{|c|}{$1.4 \%$} & \multicolumn{2}{|c|}{$13.6 \%$} & - \\
\hline
\end{tabular}




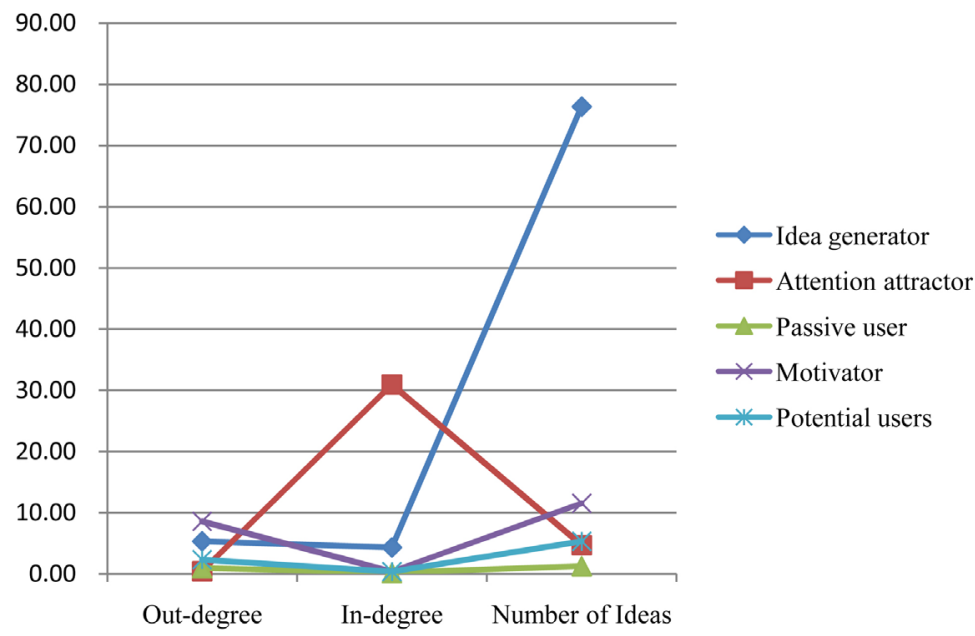

Figure 2. Five cluster solution.

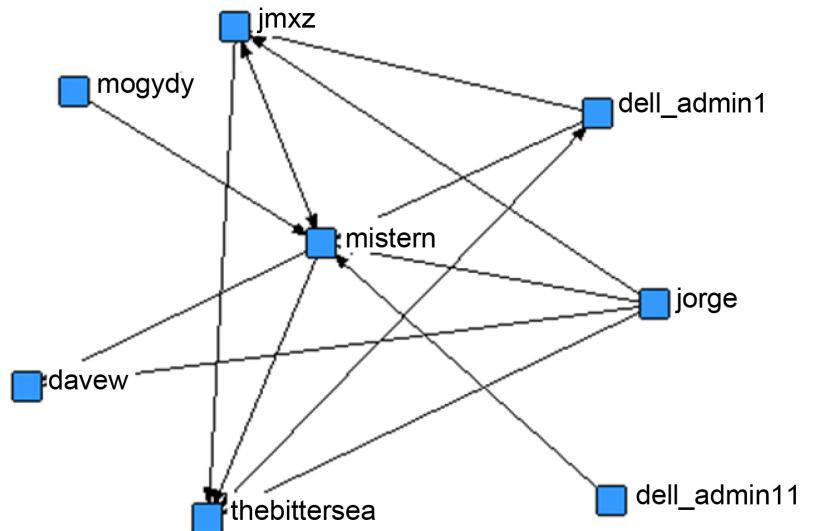

Figure 3. Idea generator (mistern), out-degree 3, in-degree 5, 67 contributions.

4.74. Explain that such users are less likely to submit ideas, but their opinions can always attract a lot of people's attention and discussion. At the same time, they also seldom actively comment on the opinions of others. A representative user individual network is shown in Figure 4.

Passive Users: 1007 people, accounting for $82.9 \%$. Similar to the results of previous studies, this number of users accounted for the largest proportion. Out-degree, In-degree, and contribution are very low, which means that their interaction and contribution behavior are maintained in a negative state. The individual network is not shown here.

Motivators: 17 people, accounting for $1.4 \%$. This type of user has the highest out-degree of 8.59, which means they submit a lot of comments in the community. The average number of contributions is 11.53 , which is at a medium level; the average of the in-degree is 0.41 , which is at a low level. It shows that such users have the enthusiasm of actively participating in the community, and can also submit a small number of ideas to promote community knowledge and sharing, but their views are less concerned. A representative user individual network is shown in Figure 5. 


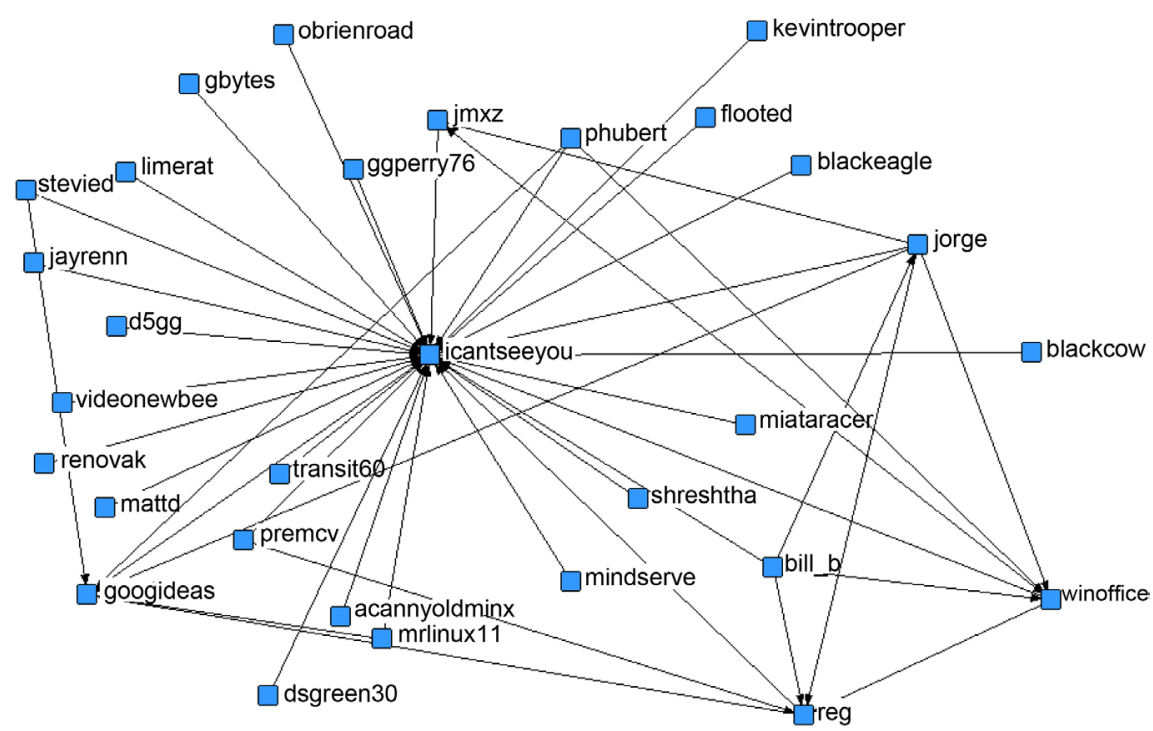

Figure 4. Attention attractor (icantseeyou), out-degree 1, in-degree 28, 9 contributions.

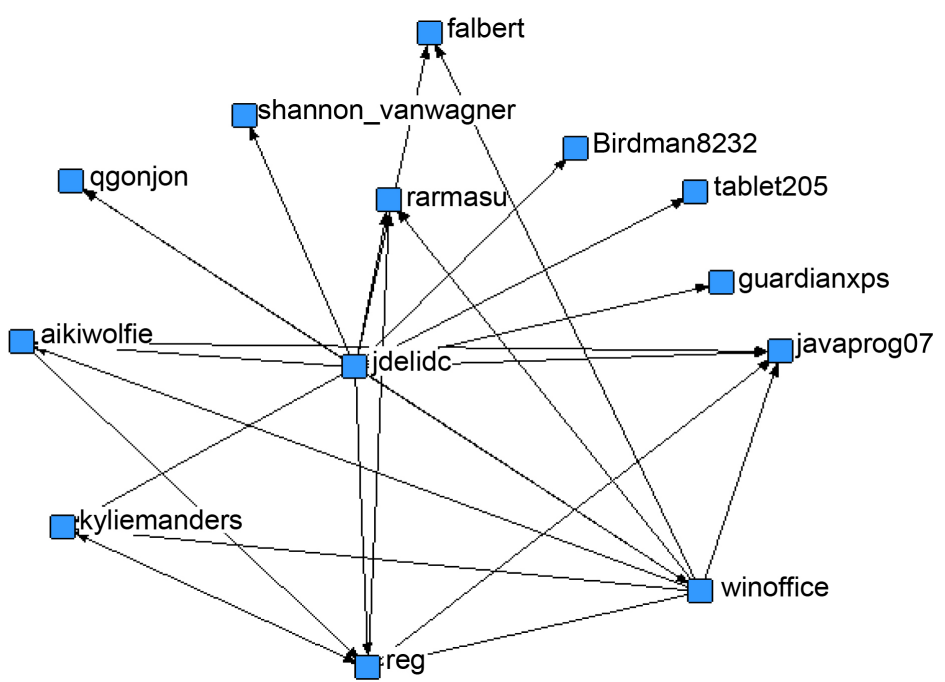

Figure 5. Motivator (jdelidc), out-degree 12, in-degree 0, 16 contributions.

Potential users: 165 people, accounting for $13.6 \%$, the average of the out-degree and contribution of this type of users were 2.34 and 5.32, respectively, both at a medium level, and the average of the in-degree was relatively low at 0.40 . It is not difficult to see that they show any interaction and contribution behavior, but they are not proactive. Therefore, this paper believes that by adopting appropriate incentives, they can stimulate their enthusiasm for participating in community interaction and contribution, and create more value for the community. A representative user individual network is shown in Figure 6.

\subsection{Network Position and the Quality of Contribution}

In the previous section, the interaction behavior and contribution behavior characteristics of five types of users were analyzed by measuring out-degree and 
in-degree and the number of submitted ideas. Next, we will examine the user's betweenness in the network to determine the heterogeneity of the network location of the five types of users. At the same time, the user's points on the platform and the number of votes obtained are used to measure the quality of the user's contribution in the community. The user's three indicator averages are summarized as shown in Table 6. It is not difficult to see that the average scores of the first type of users, the Idea generators, and the number of votes obtained are 4203.83 and 2044.17, respectively, which are much higher than other users. Therefore, this paper believes that they have the highest quality of creative submission on the platform. At the same time, it can be seen that betweeness of the Attention attractors is the highest, and the average value is 736.75 . Betweenness indicates the extent to which a node has control over resources in a network, and the higher betwenness of the node, the more the node occupies the key position of the resource and information flow, and the stronger the control ability of the resource. That is to say, such users occupy a central position in the community and play a key role in the rapid transmission of knowledge information of the community.

At the same time, it is worth paying attention to potential users. Although the

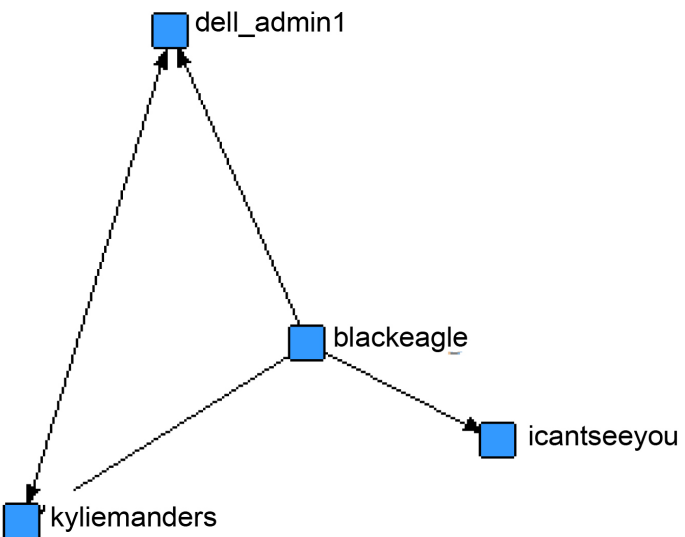

Figure 6. Potential users (balckeagle), out-degree 12, in-degree 0,16 contributions.

Table 6. Network position and quality of contribution on user roles.

\begin{tabular}{cccccccc}
\hline \multirow{2}{*}{ Variable } & \multicolumn{2}{c}{ Network Position } & \multicolumn{3}{c}{ Quality of Contribution } & \\
\cline { 2 - 6 } & \multicolumn{2}{c}{ Betweenness } & \multicolumn{2}{c}{ Votes-received } & \multicolumn{2}{c}{ Points } & N \\
\cline { 2 - 6 } User roles & Mean & SD & Mean & SD & Mean & SD & \\
\hline $\begin{array}{c}\text { Idea generators } \\
\begin{array}{c}\text { Attention } \\
\text { attractors }\end{array}\end{array}$ & 584.63 & 1148.27 & 2044.17 & 1294.98 & 4203.83 & 1180.30 & 6 \\
$\begin{array}{c}\text { Passive Users } \\
\text { Motivators }\end{array}$ & 116.75 & 572.69 & 680.53 & 569.21 & 1237.89 & 654.10 & \multirow{2}{*}{19} \\
Potential users & 14.21 & 2.02 & 76.43 & 782.88 & 113.50 & 829.25 & 1007 \\
\hline
\end{tabular}


average of the three indicators of such users is only at a relatively low level, their standard deviation shows a relatively high level, especially the standard deviation of the index is the largest. It indicates that there may be users with high quality contribution among such users. If the community gives appropriate incentives, it will be able to develop their contribution and enhance innovation performance.

\section{Discussion and Implications}

The crowdsourcing innovation model has a loosely organized form, and the participating users are free and voluntary and have a wide range of sources. In this exploratory study, we studied the community structures and user roles of a crowsourcing innovation community. The investigated community (IdeaStorm) is a typical crowdsourcing innovation virtual community, which represents a social network defined by member to member relationships. In order to more objectively reflect the network structure characteristics of the community, collecting user interaction information in the project which have been implemented by DELL. Using network measurements (in-degrees, out-degrees, betweenness) and users' contributions quantity and quality, which provided new insights into the users' roles in crowdsourcing area. This study displays the network structure and user insights into the roles and behaviors on the community.

Virtual community perspective: The results of social network analysis show that most of the users in the community are passive users, and they have less interaction and contribution behavior. Furthermore, this research found a high level of interaction between the active users. They actively participate in the community show an intense interaction behavior, expressed by high levels of in-degree and out-degree. The network centralization of out-degree value is $1.522 \%$, and the network centralization of in-degree value is $11.898 \%$. Obviously, there are some gaps between the network centralization of out-degree and in-degree, which indicates that the reciprocity and collaboration between users are low. Many scholars have shown that the higher reciprocity of innovative virtual communities means better levels of collaboration, thereby enhancing the innovation performance of the community. Therefore, enterprises should pay attention to the interaction behavior of users in the community, and take appropriate incentives in time to enhance the social enthusiasm of users.

One central contribution of this study effort is the classification of five different user roles, namely Idea generators, Attention attractors, Passive Users, Motivators, and Potential users. The identified user roles show strongly different in their interaction behavior and contribution behavior. This will provide an important insight for effectively managing community users and improving crowdsourcing innovation performance.

User roles perspective: Idea generators submit a large number of ideas in the community, who are indispensable for the successful operation of crowdsourcing innovation activities. Their ideas will inevitably increase the possibility of enterprises to explore innovative solutions, and also inspire other users' innova- 
tive thinking, which will help improve the quality of community innovation programs.

Attention attractors have a high out-degree. Although they submit relatively few comments and ideas in the community, their comments are always able to attract other users to discuss together. Their presence will certainly enhance the level of collaboration in the community. Moreover, they are key users of community information delivery. Therefore, we believe that companies should develop their communication and contribution activities to enhance the community's activity.

Passive users, similar to the results of many scholars, they occupy the largest proportion of the community, they are at the edge of the social network.

Motivators, they have a lot of outgoing relationships in the community, and also submit some ideas. They show a high level of initiative in the community's innovation activities. They actively offer feedback and suggestions to promote other users to propose or improve their ideas. Allow other users to enjoy the reciprocity of the community, thus guiding the healthy development of the community.

Potential Users, each measurement for this type of user is at a medium level. Their performance is not high or low, both in terms of behavior and quality. We believe that such users have a lot of room for development. If the management of the community is more targeted, enhance their enthusiasm for interaction, and tap the contribution of such users, they are likely to improve the quality of community activity and contribution, and create deeper value for the company.

The theoretical implication of this research is to enrich the perspective of crowdsourcing innovation research. The crowdsourcing innovation has attracted more and more attention from the academic circles, but few scholars have explored the user heterogeneity of the crowdsourcing innovation virtual community from the perspective of social network. From the practical implication of view, the organization of the crowdsourcing innovation model is loose, and users participate freely and voluntarily. These characteristics have caused the management difficulties of crowdsourcing innovation activities. Therefore, this study identifies the user roles of virtual community through social network analysis and cluster analysis, but also their characteristics are explained. Which provide a new perspective for companies to effectively manage the communities.

\section{Conclusions}

Crowdsourcing innovation is a new type of innovation model for enterprises to effectively acquire the knowledge of external network groups and achieve innovation goals. Its organizational form is relatively loose, and user participation mode is free and voluntary. A deep understanding of the heterogeneity of crowdsourcing innovation participation users is conducive to the successful development of crowdsourcing innovation model.

We choose representative crowdsourcing innovation community to study the 
network structure and user's role of virtual community, and select the user interactions and contributions in the implemented projects of the IdeaStorm community to more convincingly reflect the static network-structure characteristics of the community. On this basis, through the SNA and cluster analysis to identify the user role, five types of user roles are defined. Furthermore, the similarities and differences of network structure and contribution quality of five clusters are analyzed. The results will inevitably reflect the user participation behavior of the crowdsourcing innovative virtual community, in order to provide a new perspective for the management community. However, this study looks at the static analysis of the virtual community network structure and does not consider the evolution of users' role over time, which will be a research perspective that needs to be expanded and is meaningful in the future.

\section{Acknowledgements}

This research has been supported by Foundation of Humanities and Social Sciences of Ministry of Education of China No. 19YJA630055; Social Science Foundation of Jiangsu Province of China No. 18HQ003.

\section{Conflicts of Interest}

The authors declare no conflicts of interest regarding the publication of this paper.

\section{References}

[1] Howe, J. (2006) The Rise of Crowdsourcing. Wired, 14, 176-183.

[2] Hossain, M. and Kauranen, I. (2015) Crowdsourcing: A Comprehensive Literature Review. Strategic Outsourcing. An International Journal, 8, 2-21. https://doi.org/10.1108/SO-12-2014-0029

[3] David, P.A. and Shapiro, J.S. (2008) Community-Based Production of Open-Source Software: What Do We Know about the Developers Who Participate? Information Economics \& Policy, 20, 364-398. https://doi.org/10.1016/j.infoecopol.2008.10.001

[4] Welser, H.T., Dan, C., Kossinets, G., et al. (2011) Finding Social Roles in Wikipedia. Iconference, Seattle, 8-11 February 2011, 122-129. https://doi.org/10.1145/1940761.1940778

[5] Pedersen, J., Kocsis, D., Tripathi, A., et al. (2013) Conceptual Foundations of Crowdsourcing: A Review of IS Research. Hawaii International Conference on System Sciences, Wailea, 7-10 January 2013, 579-588.

[6] Füller, J., Hutter, K., Hautz, J. and Matzler, K. (2014) User Roles and Contributions in Innovation-Contest Communities. Journal of Management Information Systems, 31, 273-308. https://doi.org/10.2753/MIS0742-1222310111

[7] Guo, W., Zheng, Q., An, W. and Peng, W. (2017) User Roles and Contributions during the New Product Development Process in Collaborative Innovation Communities. Applied Ergonomics, 63, 106-114. https://doi.org/10.1016/j.apergo.2017.04.013

[8] Zou, Li. (2015) Research on Factors Influencing User Creative Performance in Crowdsourcing Communities and Its Application. Huazhong University of Science and Technology, Wuhan. 
[9] Xia, E., Zhao, X., Song, J., et al. (2017) The Factors Affecting Individual Performance of Network Crowdsourcing. Journal of Beijing Institute of Technology (Social Sciences Edition), 19, 79-86.

[10] Schröder, A. and Hölzle, K. (2010) Virtual Communities for Innovation: Influence Factors and Impact on Company Innovation. Creativity \& Innovation Management, 19, 257-268. https://doi.org/10.1111/j.1467-8691.2010.00567.x

[11] Fan, T. (2012) The Study of Influencing Factors of Community User Loyalty Based on Crowdsourcing Perspective. Hebei University of Technology, Shijiazhuang.

[12] Tung, W.F. and Jordann, G. (2017) Crowdsourcing Social Network Service for Social Enterprise Innovation. Information Systems Frontiers, 19, 1-17. https://doi.org/10.1007/s10796-017-9770-2

[13] Brabham, D.C. (2008) Moving the Crowd at iStockphoto: The Composition of the Crowd and Motivations for Participation in a Crowdsourcing Application. Peer-Reviewed Journal on the Internet, 13, 236-238. https://doi.org/10.5210/fm.v13i6.2159

[14] Zhang, X. and Wang, C. (2012) Network Positions and Contributions to Online Public Goods: The Case of Chinese Wikipedia. Journal of Management Information Systems, 29, 11-40. https://doi.org/10.2753/MIS0742-1222290202

[15] Fuger, S., Schimpf, R., Füller, J., et al. (2017) User Roles and Team Structures in a Crowdsourcing Community for International Development-A Social Network Perspective. Information Technology for Development, 23, 1-25.

[16] Xia, E. and Zhao, X. (2017) Research on the Factors Affecting Participation Behavior in Crowdsourcing System. R\&D Management, 29, 10-21.

[17] Dai, J. (2017) A Study on the Procedural Model of Crowdsourcing and Platform Construction: Perspective of Business Model Forming Process. Southeast University, Nanjing.

[18] Wang, Y. (2010) An Empirical Research on Users' Continuance Participation Behavior in Crowdsourcing Community. Dalian University of Technology, Dalian.

[19] Hautz, J., Hutter, K., Fuller, J., Matzler, K. and Rieger, M. (2010) How to Establish an Online Innovation Community? The Role of Users and Their Innovative Content. Hawaii International Conference on System Sciences, Honolulu, 5-8 January 2010, 1-11. https://doi.org/10.1109/HICSS.2010.221

[20] Koch, G., Hutter, K., Decarli, P., Hilgers, D. and Füller, J. (2013) Identifying Participants' Roles in Open Government Platforms and Its Impact on Community Growth. Hawaii International Conference on System Sciences, Wailea, 7-10 January 2013, 1900-1910. https://doi.org/10.1109/HICSS.2013.254

[21] Lu, Y., Singh, P.V. and Sun, B. (2014) Is Core-Periphery Network Good for Knowledge Sharing? A Structural Model of Endogenous Network Formation on a Crowdsourced Customer Support Forum. The MIS Quarterly, 41, 607-628.

[22] Li, L. (2017) Research on Customer Innovation Community Based on Social Network Theory-Roles of Members, Network Structure and Network Evolution. Beijing Jiaotong University, Beijing.

[23] Nolker, R.D. and Zhou, L. (2005) Social Computing and Weighting to Identify Member Roles in Online Communities. International Conference on Web Intelligence, Compiegne, 19-22 September 2005, 87-93. https://doi.org/10.1109/WI.2005.134

[24] Zhao, Y. and Zhu, Q. (2014) Evaluation on Crowdsourcing Research: Current Status and Future Direction. Information Systems Frontiers, 16, 417-434. 
https://doi.org/10.1007/s10796-012-9350-4

[25] Liu, X.-J. and Wang, W.-J. (2014) An Empirical Study of the Characteristics of Micro-Blog User Type and Behavior. Information Science, 32, 130-136.

[26] Toral, S.L., Martínez-Torres, M.R. and Barrero, F. (2010) Analysis of Virtual Communities Supporting OSS Projects Using Social Network Analysis. Information and Software Technology, 52, 296-303. https://doi.org/10.1016/j.infsof.2009.10.007

[27] Liu, M., Li, H. and Zhu, X. (2016) An Empirical Study of User Knowledge Sharing Level and Participation Behavior in Virtual Community. Science and Technology Management Research, 36, 155-159.

[28] Qi, G. and Li, Y. (2016) Research on the Contribution Degree of Online Users in the Open Innovation Communities for Enterprises. Science \& Technology Progress and Policy, 33, 81-87.

[29] Tian, Y. (2014) The Impact of User Interaction on Product Sales in Sharing and Guiding Community. Beijing University of Posts and Telecommunications, Beijing.

[30] Liu, J. (2009) Lectures on Whole Network Approach: A Practical Guide to UCINET. Gezhi Publishing House Shanghai People's Publishing House, Shanghai.

[31] Yu, X. and Ren, X. (1999) Multivariate Statistical Analysis. China Statistics Press, Beijing. 